\title{
Representação de Gênero nos Conflitos Armados: Uma Análise da Produção Teórica Feminista em Relações Internacionais a partir de 1980
}

\author{
Jordana Foiatto 1
}

\section{Resumo}

Analisando a produção teórica feminista das Relações Internacionais (RI) a partir de 1980, o presente artigo analisa o papel das representações de gênero nos contextos de guerra. Nesse sentido, oferece um mapeamento dos debates disciplinares acerca de gênero e feminismo nas RI. O objetivo geral consiste em responder como as representações de gênero criam estereótipos sociais nos conflitos armados por meio da criação de definições que caracterizam as ideias de masculinidade e feminilidade. Assim, para a realização do artigo, foi empregada uma abordagem qualitativa, utilizando a técnica de pesquisa documental direta nas mais variadas referências bibliográficas.

\section{Abstract}

Analysing the feminist theoretic production of International Relations (IR), since 1980, this article analyses the function of gender representation in war contexts. In this way, it offers a mapping of disciplinary debates about gender and feminism in IR. The general objective consists in responding how gender representations create social stereotypes in armed conflicts through the creation of definitions that characterizes the ideas of masculinity and femininity. Thus, for the realization of this article, it was applied a qualitative approach, using a direct documental research in varied bibliographic references.

Palavras-chave: Teoria Feminista; Identidade; Gênero; Conflitos Armados; Relações Internacionais.

\section{Introdução}

Desde sua origem, no começo do século XX, a disciplina de Relações Internacionais (RI) passou por uma série de debates tanto sobre seus temas chaves, quanto acerca das metodologias apropriadas para suas investigações. De maneira geral, as mulheres estiveram marginalizadas e excluídas desses debates e, consequentemente, da construção da disciplina.

O primeiro grande debate disciplinar ocorreu entre 1930 e 1940, quando os realistas passaram a criticar os chamados idealistas por sua avaliação otimista quanto à possibilidade de cooperação na política internacional através de acordos legais e instituições internacionais

\footnotetext{
${ }^{1}$ Graduada em Relações Internacionais pela UFPEL e, atualmente, é mestranda em Ciência Política pela mesma instituição.
} 
(TICKNER, 2001, p.22). Hans Morgenthau, um dos primeiros da escola realista, argumentava que a guerra é sempre uma possibilidade; contudo, acreditava que a procura por explicações mais amplas sobre as leis que governam a ação humana poderiam contribuir para a diminuição de desastres futuros (Ibid, p.9).

Entre 1950 e 1960, ainda segundo Tickner (Ibid, p.25), a "revolução científica" nas RI foi inaugurada pelo segundo debate, uma vez que ele apostava na possibilidade de aplicações de métodos extraídos das ciências naturais e exatas. Posteriormente, a renovação do realismo, marcado então pelo positivismo reinante nos anos 1950, foi realizada pelo autor Kenneth Waltz que adotou explicações estruturais acerca do comportamento dos Estados em relação à segurança ${ }^{2}$. Contudo, o fim da Guerra Fria e as mudanças no Sistema Internacional advindas deste evento, fizeram com que o consenso entre os realistas se desgastasse, já que a balança de poder não aparentava ser uma explicação adequada para os conflitos interestatais, ademais, as guerras entre grandes potências eram menos prováveis do que foram no passado.

$\mathrm{Na}$ década de 1980, ainda havia conversas consideráveis acerca do debate interparadigmático, o qual dava a impressão de que nenhuma teoria dominava o campo (SYLVESTER, 2001, p. 5), todavia, foi nesse contexto que a teoria crítica tornou-se uma concorrente britânica para um setor mais radical das RI. Sendo assim, para o feminismo, o fim da década de oitenta foi um marco na consolidação de sua presença na disciplina, pois foi o momento em que o pós-positivismo ${ }^{3}$, inaugurado pelo terceiro debate, surgiu em contraponto ao positivismo que até então regia como forma dominante de conhecimento do campo.

Em 1989, o autor neo-institucionalista liberal, Robert Keohane, utilizou os termos "racionalistas" e "reflexivistas" para explicar a disputa acerca da validade relativa do que estava sendo tratado como teorias explanatórias e constitutivas ou epistemologias racionalistas e reflexivistas (TICKNER, 2001, p. 26). Para ele, de acordo com Tickner, os reflexivistas chamariam atenção tanto para o papel das forças sociais, assim como para o impacto de práticas culturais até então excluídos das análises racionalistas com pretensões mais científicas e positivistas (Ibid). Assim, questões identitárias associadas com normas, discursos e instituições passaram a adquirir maior visibilidade e legitimidade na área. $\mathrm{O}$

\footnotetext{
${ }^{2} \mathrm{O}$ debate interparadigmático ou síntese neoneo, surge pelo fato de que as duas posições, neorrealismo e neoliberalismo, deveriam ser consideradas mais como posições interparadigmáticas, do que rivais, pois os aspectos dessas duas posições compartilham pontos em comum. O neorrealismo vê as RI por meio de um prisma de relações competitivas, e isso foi reconhecido pelos neoliberais, porém os últimos também defenderam os benefícios mútuos para os Estados através de maiores relações de cooperação. (LAMY, 2008: 132)

${ }^{3}$ Para Yosef Lapid, o pós-positivismo inclui uma variedade de abordagens - teoria crítica, sociologia histórica, pós-modernismo, assim como a maioria das feministas. Nenhuma delas se identifica com o debate interparadigmático, ou seja, não adotam a metodologia científica-social convencional das RI (TICKNER, 2001: 26)
} 
presente artigo de TCC, portanto, compartilha das preocupações pós-positivistas inauguradas pelo terceiro debate.

As teóricas feministas das $\mathrm{RI}^{4}$ - muitas das quais são céticas quanto à revolução científica da disciplina - tendem a se identificar com o lado reflexivista do debate. As obras "Women and War" (1987) de Jean Elshtain e "Bananas, Beaches and Bases: Making Feminist Sense of International Relations" (1989) de Cynthia Enloe são exemplos de obras pioneiras do feminismo na disciplina. Ambas autoras são reconhecidas e responsáveis por incluir o gênero como categoria de análise na política internacional, algo praticamente inexistente nas demais correntes teóricas. Dessa maneira, as autoras buscaram em instituições e normas do sistema internacional, explicações para as hierarquias e assimetrias nas relações entre gêneros, assim como as instâncias de constituição de identidade de homens e mulheres dentro e fora das mesmas. Sobretudo, procuraram dar visibilidade às mulheres como sujeitos e, também, protagonistas do rico universo que compõem todas as sortes das "relações internacionais".

A problemática escolhida para realização deste TCC consistiu em responder como as representações de gênero criam e reforçam estereótipos identitários através da definição de "masculinidade" e "feminilidade" nos conflitos armados. Parte-se da premissa de que a construção identitária é responsável por reforçar o binarismo essencialista nos conflitos armados, pois enquanto a mulher geralmente é associada a um papel maternal e pacífico em cenários belicosos, o homem é associado ao uso da força e violência. Assim, a hipótese teórica de trabalho é de que os papéis sociais nos conflitos podem ser móveis e dinâmicos, e não, estáticos, pré-definidos e fixos.

O objetivo geral dessa proposta teórica consiste em responder como as representações de gênero criam estereótipos sociais nos conflitos armados por meio da criação de definições que caracterizam as ideias de masculinidade e feminilidade. Para isso, os seguintes objetivos específicos foram perseguidos: a) revisar a teoria feminista das RI e sua entrada na disciplina, como já brevemente exposto; b) identificar as principais contribuições da teoria feminista para a área específica da segurança internacional, enquanto área masculinizada por excelência; e, c)explorar as possibilidades acerca dos papéis associados a "masculinidade" e "feminilidade" nos contextos onde imperam a violência.

Esta pesquisa exploratória está ancorada em uma abordagem qualitativa, tendo em vista que não serão aplicados procedimentos estáticos ou qualquer outro tipo de quantificação.

\footnotetext{
${ }^{4}$ A teoria feminista produzida na área de RI é composta por vertentes diversas, criando assim, um rico debate composto por diferentes perspectivas. Argumenta-se que não há uma voz singular no feminismo, considerando os diferentes contextos em que as mulheres estão inseridas. Tendo isso em vista, nesta pesquisa, tanto mulheres como homens não são tratados como sujeitos únicos.
} 
As duas principais técnicas de pesquisa utilizadas foram a bibliográfica e a documental, ambas foram empregadas no trabalho como um todo, visto que o mesmo intenciona ser uma revisão bibliográfica a partir da utilização de dados secundários. Ressalta-se, a partir disso, a limitação desta pesquisa já que a mesma não tem como objetivo a produção de novos dados.

A justificativa para a realização dessa pesquisa reside na tentativa de "desmarginalização" do feminismo na disciplina, haja vista sua importância para a análise da guerra como um todo, e especialmente, para a investigação sobre a inserção das mulheres no ambiente internacional e sua relevância para a sustentação das estruturas sistêmicas tradicionais. Na primeira seção, será analisada a entrada das pensadoras feministas na disciplina e toda a discussão sobre a marginalização da questão de gênero na área. Em seguida, a segunda seção, mostrará como a segurança internacional é vista através das lentes feministas e a contribuição dada a essa área tradicional de estudos. Por fim, a última seção, se aprofundará nas questões de representação de gênero, procurando responder como os estereótipos de feminilidade e masculinidade são construídos e reproduzidos pelo sistema da guerra.

\section{A entrada do feminismo nas Rl: o debate marginalizado}

Foi somente em 1989, quando Robert Keohane publica o ensaio "International Relations Theory: Contributions of a Feminist Standpoint", que os teóricos do mainstream passam a observar com mais cautela a produção teórica feminista. Até então, os mesmos invisibilizavam por completo a presença e ação das mulheres não só nas relações de poder do Sistema Internacional, como também nas relações de poder internas da academia. Por isso, este artigo apresenta de modo crítico, a entrada da teoria feminista nas RI sendo justamente nesse momento, quando Keohane parece tentar, sem sucesso, ser o tutor dessas teóricas.

Utilizando a teoria feminista como seu próprio objeto de análise, o autor convida as teóricas para contribuir em uma "conversa emergente" e deixa suas impressões preliminares acerca dessa contribuição. Para embasar seu argumento, Keohane adota a tipologia da autora Sandra Harding (1986) a qual aponta para três tipos de feminismo: o standpoint, também conhecido como feminismo de ponto de vista,o empiricista e o pós-moderno.

Segundo Keohane, o feminismo empiricista compreenderia que os Estados e o sistema interestatal são fundamentalmente estruturas "gendradas" ${ }^{5}$ de dominação e interação

\footnotetext{
${ }^{5}$ Segundo Lauretis (1987), a utilização do termo "gendrado" (gendered) serve para designar algo "marcado por especificidades de gênero".
} 
(KEOHANE, 1989, p.245). Com certa relutância, ele define o feminismo pósmoderno,apontando que o mesmo resiste à ideia da existência de uma verdade universal e é composto por uma variedade de tendências. A partir de uma visão mais amigável para com o feminismo standpoint ${ }^{6}$, o autor considera que esta vertente feminista proporciona um "ponto de partida promissor para o desenvolvimento de uma teoria feminista de RI” (ibid).

A importância do feminismo standpoint, para Keohane, estaria inserida na necessidade de revisão de conceitos clássicos das RI como os de soberania, poder e reciprocidade. Tendo isso em vista, Keohane aponta para a possibilidade de uma aliança entre a emergente teoria feminista e o institucionalismo neoliberal, pois, segundo ele, ambos enfatizam o poder como a habilidade de agir em concerto, a reciprocidade difusa e o papel das redes transnacionais como hierarquia válida (ibid, p. 250). É imprescindível notar que o otimismo de Keohane paira unicamente sobre o feminismo standpoint, enquanto as outras vertentes citadas são consideradas menos prósperas.

Ainda em 1989, a autora Cynthia Enloe dá origem a um dos clássicos do feminismo em RI - "Bananas, Beachesand Bases: "Making Feminist Sense of International Politics". Nesta obra pioneira, Enloe convida os leitores para uma jornada investigativa que analisa tanto a vida quanto as experiências de diferentes mulheres nas mais variadas camadas d apolítica internacional.Ao se afastar dos assuntos centrais e tradicionais das RI da época, a teórica faz um novo mapeamento das fronteiras que limitam a disciplina, argumentando que “o privado é internacional”, na extensão da máxima feminista "o pessoal é político". Essa afirmação implica que as relações que até então eram consideradas privadas são, na verdade, infundidas por poder e também fazem parte do mundo internacional (ENLOE, 1989, p.348). Além disso, as relações pessoais - ou privadas - são imbuídas de um poder desigual, apoiadas pelas autoridades públicas (ibid).

Cinco anos depois, tendo em vista as críticas e a maneira como Keohane apresenta a tipologia do feminismo em seu artigo, a autora Cynthia Weber publica uma resposta em 1994, "Good Girls, Little Girls and Bad Girls: Male Paranoia in Robert Keohane's Critique of Feminist International Relations". Weber (1994) se refere à construção de dois corpos no artigo do autor canônico: primeiro, um corpo literário feminista que é o objeto de análise do texto e, segundo, um corpo autoral do próprio Keohane que vê, escreve e disciplina o objeto de análise a partir de uma posição sujeita a autorização (ibid, p.337), culminando no que a

\footnotetext{
${ }^{6}$ Tal vertente argumenta que a experiência das mulheres marginalizadas da vida política provê perspectivas em questões sociais, garantindo compreensões válidas sobre a política internacional.
} 
autora denomina como momentos de "paranoia masculina"7. Para ela, a crítica de Keohane tenta impedir que o feminismo transpassasse limites existentes na disciplina; e, se isso não for suficiente, o autor seria capaz de criar novas barreiras de modo que o corpo literário feminista não ameaçasse os limites impostos nos primeiros debates.

Weber também problematiza a adoção da tipologia do feminismo no texto de Keohane. Segundo a crítica da autora, o modo de olhar para o feminismo condiciona o corpo literário feminista ao que deve ser visto, mas não ouvido - anão ser que essas vozes sejam mediadas através da interpretação textual de Keohane (ibid, p.338). Diferentemente de Sandra Harding (1986), Weber argumenta que ao invés de Keohane olhar através das lentes feministas para analisar diversas questões, o autor olha para as mesmas a partir de uma posição externa. Desse modo, as três categorias empregadas no texto de Keohane são transformadas a partir do seu ponto de vista, ou seja, a visão do autor sobre as RIcomo um todo não se altera.

Assim, o emprego da tipologia de Harding por Keohane soou problemático tanto por aplicar apenas sua nomenclatura, deixando de lado seu conteúdo explicativo, como também por gerar a impressão de um corpo literário feminista composto por unidades opostas ao invés de um corpo multifacetado. Dessa maneira, Weber argumenta que o corpo feminista aparece mutilado no texto de Keohane (ibid, p.340). Assim, a categorização do feminismo pelo autor inspirou o título do artigo de Weber, no qual as "boas" meninas se apresentam como uma analogia para as feministas standpoints, as "pequenas" meninas para as empiricitas e as meninas "más” como as pós-modernas. Segundo Weber (1994):

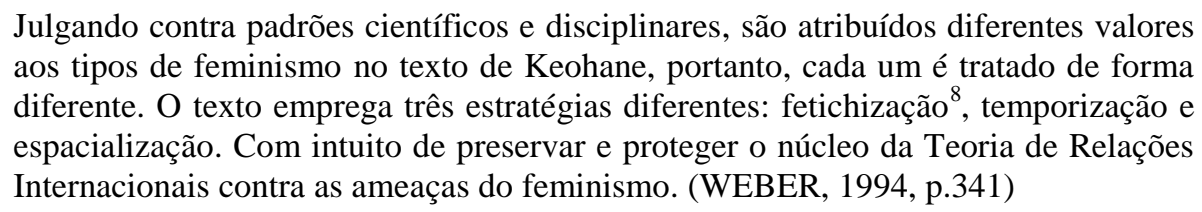

Weber denota que ao olhar somente para a compatibilidade do feminismo standpoint com o institucionalismo liberal, o texto de Keohane acaba causando uma obstrução visual sobre suas outras características. Logo, além de se tornar um objeto parcial do texto, esta vertente ainda perde seu valor originário para ser transformada em um "institucionalismo feminista”.

\footnotetext{
${ }^{7}$ Segundo Weber (1994), a paranoia masculina se refere à resposta temerosa do patriarcado para a perda endêmica de fronteiras para condição de subjetividade na contemporaneidade, chamada pós-moderna, vida Americana.

${ }^{8}$ Para Emily Apter (1991), fetiche refere-se a objetos que se assemelham a nós e são formas objetivadas dos nossos desejos.
} 
De outro modo, o feminismo empiricista ou as "pequenas meninas", na visão de Keohane, tenderia a descrever ao invés de teorizar. Segundo Keohane, este suposto atraso no desenvolvimento científico disciplinar de tal vertente poderia ser solucionado se o feminismo empiricista se tornasse um aliado de sua "irmã mais velha", o feminismo standpoint (ibid, p. 345). Tendo isso em vista, Weber aponta que se a visão de Keohane for levada em conta, o feminismo empiricista está condenado a um destino que não é de sua própria escolha.

A paranoia masculina de Keohane, segundo Weber, se sobressai quando a questão gira em torno das feministas pós-modernas ou as "meninas más" (ibid). O autor acredita que esta vertente deveria ser "amputada" das demais;por conta de suas qualidades elusivas, ele não consegue aceitar sua posição autoral, científica ou disciplinada. Para Weber, isso gera dois resultados: o primeiro é que este feminismo não pode ser feito para respeitar as leis da ciência ou os objetivos da disciplina; e o segundo,por conta de sua incapacidade de identificação com o feminismo pós-moderno, o texto de Keohane não consegue fetichizá-lo (ibid, p.346) - ou seja,o mesmo não encontrou uma maneira plausível de situar as "meninas más" dentro da fronteira que demarca a ciência propícia para a disciplina, optando por deixá-las de fora dessas limitações.

Em síntese, o artigo de Keohane tentou enquadrar o feminismo ao lado da "lei" da disciplina. Segundo Weber, se a tática fosse bem-sucedida, o corpo autoral doautor seria reconfigurado como o "irmão mais velho" das "boas meninas" (ibid, p. 347).Para a autora, as pretensas"boas intenções" de seu artigo para com as teóricas são equivocadas, pois ao invés de garantir maior visibilidade às vozes feministas na disciplina, o texto de Keohane parece querer silenciá-las ainda mais.

Numa tentativa de compreender os desentendimentos surgidos nessa discussão, entre as feministas e alguns teóricos positivistas, em 1997, Ann Ticknerpublicou o artigo "You Just Don't Understand: Troubled Engagements Between Feminists and IR Theorists". De acordo com Tickner (1997, p. 612), desde sua introdução no núcleo das RI, o feminismo tem sido sutilmente ignorado ou criticado por ser mais adequado para uma "leitura de cabeceira" do que para a discussão acadêmica. Consequentemente, críticas como esta geralmente advém de teóricos positivistas, os quais são conhecidos por embasar suas teorias em uma abordagem quantitativa - que ela denomina como "abordagem de solução de problemas" -por meio da análise de dados.

Em sua análise, Tickner aponta para três dicotomias chaves para entender essa discussão: a teoria positivista e a teoria crítica, o positivismo eo pós-positivismo e, por fim, a dicotomia não social e social. Quanto à primeira dicotomia, Tickner argumenta que a 
indisposição dos positivistas de reconhecer a legitimidade de novas abordagens na disciplina é uma das maiores causas do silêncio advindo do núcleo dominante das RI em relação às abordagens feministas.

O método da "solução de problemas" além de apontar que toda teoria deve ter um propósito, argumenta que a construção de teoria deve ser baseada na possibilidade de controlar e prever eventos no futuro, assim como entender resultados sólidos e tangíveis. As feministas, em contraponto, negam a necessidade dessas premissas fundamentais. Sendo assim, as teóricas opõem-se à ordem vigente no mundo para questionar como a mesma surgiu; consequentemente, não aceitam as leis da natureza para entender a política internacional,tal como fazem as teorias do mainstream. Ademais, as feministas argumentam que a crença desses pensadores em um mundo objetivo e determinista é amplamente moldada pela subjugação feminina naturalizada.

Em relação à segunda dicotomia, enquanto o positivismo é considerado uma filosofia a qual argumenta que o conhecimento autêntico é o que advém do método científico, o póspositivismo é uma escola de pensamento que valoriza a pesquisa qualitativa ao invés da quantitativa; desse modo, ele questiona a objetividade a partir de métodos que tencionam a desconstrução. De acordo com Tickner (1997):

\begin{abstract}
Apesar das abordagens feministas não estarem conectadas necessariamente com o pós-positivismo, há uma forte ressonância por uma variedade de razões, incluindo um comprometimento com o pluralismo epistemológico assim como com certa sensitividade ontológica. (...) Enquanto muitas feministas veem regularidades estruturais, como gênero e patriarcado, elas as definem como socialmente construídas e variáveis ao longo do tempo, lugar e cultura, ao invés de naturais e universais. (TICKNER, 1997, p. 619)
\end{abstract}

As relações sociais são fundamentais para o feminismo, especialmente em termos de consequências e causas relações estruturais desiguais entre homens e mulheres. Sendo assim, as feministas argumentam que as RI foram socialmente construídas com base em associações equivocadas da masculinidade com poder, autonomia, racionalidade e esfera pública, enquanto fraqueza, dependência e esfera privada foram relacionadas com a feminilidade. Tendo em vista a terceira dicotomia apontada por Tickner, as feministas acreditam que as análises dominantes da disciplina seriam "associais", e por isso, negligenciadas pelos mesmos.

Logo, esta pesquisa defende os pontos de vista de Tickner (1997) e Weber (1994) que sustentam a ideia de um feminismo sem tutela, ou seja, um feminismo autônomo dentro da disciplina, diferentemente do que Keohane intencionou no seu artigo paternalista. Muitas feministas têm objetivos emancipatórios, particularmente com intuito de alcançar igualdade 
para as mulheres através da eliminação de relações gendradas firmadas na estrutura das RI (TICKNER, 1997, p.616). Tendo isso em vista, apresenta-se aqui a tentativa de "desmarginalização" da teoria feminista - composta por suas diversas vertentes -, pois a mesma permanece nas margens da produção acadêmica da disciplina.

\section{A abordagem feminista na área tradicional da segurança internacional: principais contribuições}

O debate sobre a ampliação do conceito tradicional de segurança foi possível, a partir da década 1980, quando as teorias críticas ganharam maior visibilidade na disciplina. Para os diferentes teóricos desta linha, a revisão conceitual em questão deveria ir além das distinções hierárquicas binárias aplicadas nos estudos clássicos; por isso, a análise de identidades foi considerada fundamental para o entendimento do comportamento estatal em assuntos de segurança. Nesse sentido, a teoria feminista busca entender - a partir da aplicação do gênero como categoria de análise - como a segurança dos indivíduos e dos grupos está comprometida com a violência física e estrutural em todos os níveis de análise (TICKNER, 2001, p. 48).

O gênero não é levado em consideração nas análises positivistas acerca da segurança internacional. Tendo isso em vista, as feministas argumentam que os estudos clássicos são elaborados por meio de uma "linguagem masculinizada", a qual oculta o papel das mulheres na sociedade (ibid, p. 49). A partir disso, algumas vertentes do feminismo investigam como as valorizações associadas a uma masculinidade dominante são capazes de influenciar na política externa dos Estados. Assim, o foco do feminismo no que tange aos estudos de segurança internacional consiste nos acontecimentos que eclodem durante o período de conflito armado, podendo, desse modo, analisar suas causas e términos (ibid, p. 4).

Algumas feministas da disciplina consideram a criação do Estado Westfaliano um mito, expondo a partir disso, como a política global contribui para aumentar a insegurança dos indivíduos, principalmente os marginalizados e subalternizados. Nesse sentido, Tickner (ibid, p. 43) apresenta uma problemática quanto ao conceito de Estado, argumentando que o mesmo parece ser inapropriado para muitos territórios que servem de arena para conflitos étnicos, já que sua legitimidade governamental no pós-guerra geralmente advém do sistema internacional, e não de sua própria população. Segundo Skjelsbæk e Smith (2001),

Do começo de 1990 até o fim da década, o mundo presenciou 118 conflitos armados, no decorrer dos mesmos, aproximadamente 6 milhões de pessoas foram mortas. Poucas dessas guerras aconteceram entre dois Estados soberanos, a maioria foram guerras civis frequentemente institucionalizadas através do envolvimento de atores externos como financiadores, fornecedores, treinadores ou combatentes. [...] 
Praticamente todos os assassinatos ocorridos nas proximidades do conflito, foram executados por homens. (SKJELSBÆK \&SMITH, 2001, p.3)

Os conflitos internos do Sul global frequentemente foram ocasionados por mudanças nas políticas domésticas de regimes que, muitas vezes, obtinham apoio de grandes potências através de intervenções externas (TICKNER, 2001, p. 41). Algumas feministas apontam para o fato de que a insegurança desses países de periferia é criada pela falha na integração de grupos sociais no processo político.

Ao término da Guerra Fria, a partir do declínio na predominância dos assuntos estratégicos na disciplina, da ascensão dos conflitos étnicos e do "choque de civilizações" "observou-se a necessidade de renovação dos conceitos tradicionais do campo de segurança. Para Tickner (ibid, p. 2), as teóricas feministas sentiam-se mais à vontade com esse redirecionamento de foco na disciplina em comparação ao domínio praticamente único dos estudos estratégicos. A investigação feminista ao se voltar do nível micro para o global, do pessoal para o internacional, permitiu demonstrar como as análises a partir de uma perspectiva macro podem ser prejudiciais para grupos locais e individuais, expondo as relações sociais de maneira hierárquica (Ibid). Pensando na visualização das mulheres e seus papéis nos estudos de segurança, Pettman (2005) argumenta que:

\begin{abstract}
guerra e paz são assuntos feministas, pois as mulheres estão localizadas de maneira particular e perigosa nos discursos e políticas de guerra. A violência, incluindo a governamental, é frequentemente sexualizada. Os entendimentos e revisões das feministas contemporâneas sobre os estudos de segurança, apesar de não serem monolíticos, revelam que os processos de guerra e paz contêm um elemento de gênero, e assim, sugerem estratégias para um mundo mais seguro. (PETTMAN, 2005, p. 62)
\end{abstract}

As feministas apontam para o aumento exponencial no número de baixas de civis que cresce constantemente nos conflitos armados, questionando dessa maneira, o mito da guerra como provedora de proteção para mulheres e crianças - classificadas como "vulneráveis" por meio de estereótipos de fragilidade e fraqueza (TICKNER, 2001, p. 48). Este mito de proteção cria a imagem de um soldado guerreiro e herói que sacrifica sua vida para salvar os indivíduos 'desprotegidos' da sociedade. Dessa maneira, essa construção social é responsável tanto pelo recrutamento de jovens para as forças armadas quanto pela conquista de legitimidade da violência em tempos de guerra.

Em contraste com o que as correntes teóricas hegemônicas de RI apontam, a capacidade bélica de um Estado não implica a garantia de sua segurança contra ameaças de

\footnotetext{
${ }^{9}$ Tese controversa desenvolvida pelo cientista politico conservador, Samuel P. Huntington, a qual afirma que as identidades culturais e religiosas seriam a principal fonte de conflito após o término da Guerra Fria.
} 
"outros" " É possível considerar esta, uma das contribuições fundamentais de algumas teóricas feministas da disciplina - as quais estão empenhadas na elaboração de uma revisão crítica da literatura dominante acerca da segurança internacional.Diante disso, Tickner caracteriza a militarização como uma das principais ameaças à segurança da população (Ibid, p. 42). Complementando, de acordo com Chenoy e Vanaik (2001):

\begin{abstract}
As sociedades militarizadas são mais hierárquicas e patriarcais em comparação com as não-militarizadas, e até as sociedades com estruturas democráticas podem tornarse cada vez mais militarizadas. Essas sociedades, então, tendem a ser mais opressivas para as mulheres, tanto na esfera pública como na privada. Consciência e linguagem tornam-se militarizadas. A resposta imediata para a maioria das dissensões é a coerção, incluindo a militar. Tudo isso aponta para uma necessidade urgente de trazer as mulheres para a esfera pública nessas sociedades.(CHENOY \& VANAIK, 2001: 131)
\end{abstract}

Segundo Zalewski e Parpart (2008, p. 152), o mito heroico do soldado guerreiro é considerado parte essencial que compõe a identidade nacional e a masculinidade hegemônica, tendo conquistado credibilidade através da estrutura narrativa de muitas histórias de guerra e imagens culturais. O mito em questão contrasta com os casos de estupro cada vez mais recorrentes nos cenários hostis, principalmente nos conflitos étnicos. Por conta de sua banalização para opinião pública, os estupros em tempos de guerra frequentemente são considerados acidentes inevitáveis. Em contraponto, Tickner (2001, p. 50) argumenta que essas violações podem ser utilizadas, conscientemente, como uma estratégia militar sistemática, podendo enfraquecer a identidade de comunidades em sua totalidade. Embora o estupro seja ilegal sob todos os códigos militares e pelo fato de sua punição ser, frequentemente, a pena de morte, a aceitação de sua inevitabilidade quando executado por soldados é muitas vezes tão fatalista quanto tolerante (SKJELSBÆK e SMITH, 2001).

Os militares também possuem uma ligação direta com a prostituição nas zonas de conflito, fato que é descrito por Enloe (1989 apud Tickner, 2001, p. 50) quando a mesma descreve as estruturas sociais em torno das bases militares dos Estados Unidos, no exterior, nas quais mulheres são sequestradas e vendidas para prostituição. Em consequência, é possível observar que as mulheres não podem ser protegidas pela militarização, ao mesmo tempo em que são as vítimas centrais das hostilidades.

Enquanto a maioria da população masculina está envolvida diretamente com o conflito, podendo em muitos casos até ser dizimada, as mulheres tornam-se agentes na guerra

10 A noção de "perigo" serve para reafirmar espaços morais criados para definição de fronteiras éticas e territoriais através do estabelecimento das dicotomias "dentro/fora", "eu/outro", "doméstico/estrangeiro". A partir de um "discurso do medo" que mostra o fora, o outro, o estrangeiro, como fonte de perigo, os Estados reafirmam suas fronteiras éticas, ou, suas identidades, e consequentemente, suas fronteiras territoriais (BARROS, 2006.: 73) 
durante o período belicoso. Além da sustentação de suas respectivas famílias, as mesmas ficam responsáveis por preencher as vagas de trabalho que antes eram ocupadas por homens. É importante salientar que a aquisição da autonomia garantida pelas mulheres durante esse período em específico, geralmente é perdida no pós-guerra com a reconstrução da estrutura estatal. Assim, independente da participação das mulheres na guerra e nos conflitos armados, até mesmo como combatentes, elas rotineiramente voltarão para os cuidados da casa e sua contribuição provavelmente será esquecida com o fim das hostilidades (PETTMAN, 1996, p. 93).

Assim, o período hostil possibilita uma expansão temporária do papel público das mulheres e dos tipos de trabalho que elas podem ter acesso durante a luta armada. Assim sendo, o fato desse processo regredir com o fim da guerra demonstra o privilégio masculino daqueles que voltam da batalha, ganhando cidadania plena e retomando rapidamente seu status. Os conflitos, então, ocorrem através de um acordo implícito, o qual define que os papéis de gênero foram suspensos durante a guerra e o retorno da paz significa o reestabelecimento da ordem anterior às hostilidades. Segundo Pettman (1996, p. 9), a domesticação das mulheres é um processo cultural e político multifacetado; é preciso um trabalho ideológico intenso para voltar a 'normalidade' e 'naturalizar' o lugar das mulheres na sociedade.

No âmbito da tomada de decisões da política externa, as mulheres geralmente são invisíveis; por conseguinte, raramente são consideradas como provedoras de segurança, afinal sua imagem éincompatível com o estereótipo de um expert de segurança internacional. Um exemplo da inferioridade de tudo o que é considerado "feminino" na tomada de decisão de alto escalão, é apresentado em Cohn e Ruddick (1993);

[...] nós remodelamos um ataque em particular, usando parâmetros ligeiramente diferentes, e descobrimos que em vez de haver 36 milhões de mortes imediatas, haveria apenas 30 milhões. E todo mundo estava sentado em torno acenando com a cabeça dizendo: 'isso é ótimo, apenas 30 milhões' quando, de repente, ouvi o que estavam dizendo. E eu deixei escapar: 'Espere, eu acabei de ouvir como estamos falando - apenas 30 milhões! Apenas 30 milhões de seres humanos mortos instantaneamente? O silêncio caiu sobre a sala. Ninguém disse uma palavra. Eles nem sequer olharam para mim. Foi horrível. Eu me senti como uma mulher. (COHN \& RUDDICK, 1993, p. 416)

Segundo Cohn (apudTickner, 2001, p. 53), a linguagem que usamos molda a maneira como vimos o mundo e também como agimos nele. Assim, o discurso masculinizado dos experts de segurança, exemplificado na última citação, sugere que esse é o único modo válido em discutir sobre segurança nacional e ser levado a sério no meio estratégico, demonstrando 
que os limites do que pode ser dito, constrange a habilidade de pensar amplamente sobre segurança. Nesse sentido, algumas teóricas feministas desenvolvem análises de diferentes discursos, pois acreditam que estes ajudam a legitimar um tipo de ordem social militarizada que sobrevaloriza o uso da violência estatal.

Um “discurso gendrado", segundo Cohn (1993, p. 230), pode ser definido como um sistema de significados, maneiras de pensar, imagens e palavras que moldam a forma como os indivíduos vivenciam, entendem e representam-se como homens e mulheres(apudCOOKE \& WOOLLACOTT, 1993). Esse sistema é baseado em características humanas dicotômicas, as quais geralmente são mutuamente exclusivas. As dicotomias frequentes nos discursos são associadas com a masculinidade e a feminilidade, nesses casos, ocorre uma sobrevalorização de tudo o que for relacionado com o masculino. O impacto deste tipo de discurso, no âmbito da tomada de decisão que envolve questões de segurança, pode ser visto no fato de que algumas preocupações, informações, ideias e interesses são relacionados com o feminino, sendo, portanto, desvalorizados.

Para Cohn (2006 apud MONTE, 2010, p. 78), o discurso tecno-estratégico depende da separação radical entre pensamento e sentimento, na necessidade reconhecida de excluir emoções da racionalidade ou, ainda, excluir o que possa ser entendido como emoções. Em resumo, na área da segurança internacional, o feminismo aponta que as possibilidades de conflito não diminuirão se as desigualdades hierárquicas de gênero forem conservadas; e ainda, sustenta que a permanência do privilégio associado aos estereótipos masculinos, nas políticas externas dos Estados, contribui para legitimar a guerra e a militarização.

Assim, na produção teórica feminista, é possível notar um maior cuidado com o emprego de dicotomias gendradas que criam visões simplistas como a do homem guerreiro e da mulher pacífica, pois isso acaba desempoderando tanto as possibilidades de paz quanto a agência das mulheres. Logo, a contribuição fundamental do feminismo para a área consiste em repensar conceitos centrais das RI, como segurança e paz. As teóricas buscam desenvolver essa revisão não de uma maneira idealizada, geralmente associada com mulheres, e sim, de forma mais ampla, em termos multidimensionais que incluem a eliminação de hierarquias sociais - como as de gênero - que conduzem às injustiças econômicas e políticas.

\section{Os efeitos da representação de gênero nos conflitos armados: a capacidade de alterar a dinâmica da guerra através da construção de identidades}


A obra clássica de Cynthia Enloe (1989) expõe alguns exemplos expressos em imagens da minoria inquestionável de mulheres no cenário político internacional. A partir dessa observação se faz necessário um questionamento sobre as masculinidades presentes nas configurações tanto da esfera pública, como da privada. Ademais, Enloe atenta sobre a criação da ideia de um "mundo perigoso" que vem se desenvolvendo a partir do término da Guerra Fria e, especialmente, após o atentado às Torres Gêmeas (ibid, p. 29).

A partir do onze de setembro, é possível constatar que as ações securitárias justificadas para fins da obtenção de resultados na "Guerra ao Terror" e a construção do discurso baseado no medo servem para fortalecer a hegemonia de certos tipos de masculinidades, enquanto subordina as mulheres às características desvalorizadas da feminilidade (ibid, p. 30). Pelo senso comum, a ideia de que a sociedade está inserida em um mundo perigoso, em busca da apreensão de um inimigo comum, faz com que os homens sejam vistos como agentes da proteção e as mulheres como atores que precisam ser protegidos. A reafirmação dessas lógicas dualísticas apelativas e familiares - nós/eles, bom/mau, protetor/protegido - são, como sempre, revestidas com imagens essencialistas de gênero (ZALEWSKI e PARPART, 2008, p. 5).

Assim, os conceitos de "masculinidade" e "feminilidade" geralmente são usados para definir uma noção estática e simplificada de identidade, ou também, podem ser baseados em uma ideia simplista e irreal de diferenças entre homens e mulheres. É imprescindível notar que as representações de gênero são dinâmicas, pelo fato de que as mesmas se alteram de acordo com diferentes fatores como, por exemplo, tempo, cultura e geração. Segundo Weston (2002), o gênero vem provando ser incrivelmente maleável, adaptando-se às novas circunstâncias ao invés de perecer em resposta às demandas por mudança (apud ZALEWSKI \& PARPART, 2008: 3). Dessa maneira, a utilização dos termos "masculinidade" e "feminilidade" são essenciais para discutir toda a questão de ambiguidade de gênero. De acordo com Ruddick, Cohn e Hill (2005),

Todas as culturas são compostas por corpos biológicos de homens e mulheres, mas o significado de "masculino" e "feminino" varia conforme cultura e mudanças na mesma ao longo do tempo. Quais os traços de capacidades ou personalidades que são esperados de homens e mulheres; quais os tipos de atividades, empregos e papeis familiares que são considerados apropriados para eles; o que significa ser um "homem de verdade" ou uma "mulher de verdade". Tudo isso faz parte do significado cultural dado à diferença biológica. (COHN, RUDDICK e HILL, 2005, $\mathrm{s} / \mathrm{p})$

Quanto ao simbolismo presente nestas práticas de gênero, RaewynConnell aponta que o processo de comunicação é reconhecido como elemento vital do processo social (2000, p. 37). A partir disso, torna-se fundamental observar que as estruturas simbólicas - inseridas na 
comunicação social por meio de discursos, leis e vocabulários - são responsáveis pelo entendimento do gênero através de oposições simbólicas, reforçando ainda mais as dicotomias que envolvem essa temática.

Dessa maneira, é possível constar que esse padrão de discurso também cria as bases para outros aspectos da vida e de culturas (ibid, p. 229). O impacto das estruturas simbólicas gendradas, no âmbito da tomada de decisão, pode ser visto no fato de que algumas preocupações, informações, ideias e interesses que estejam relacionados ao feminino são geralmente menosprezados. Sendo assim, se, como sociedade, começarmos a acreditar que os corpos femininos são fracos, emocionais, irracionais, passivos, maternais e necessitados de proteção, nós iremos pensar que é natural e certo que a vida da maioria das mulheres seja limitada à esfera privada do lar e da família (COHN, HILL \& RUDDICK, 2005, s/p).

É fundamental a observação de que o patriarcado é estruturado através de certos tipos de masculinidades privilegiadas, enquanto a maioria das mulheres ocupa uma posição de subordinação e dependência. Devido a essa condição, de acordo com Enloe (1989, p. 31), muitos homens em cenários conflituosos podem fazer uso da feminilidade para diminuir o status de seus rivais, ações como esta tentam expropriar as características masculinas hegemônicas - tais como racionalidade, coragem e força - dos opositores.

Ainda de acordo comEnloe (ibid), o manejo masculinizado da feminilidade além de estar presente em outros setores,também acontece nas políticas nucleares internacionais. Assim, para as feministas que se dedicam aos estudos de segurança, é imprescindível considerar as armas de destruição em massa como objetos políticos, pois nos debates acerca da segurança, a importância simbólica desse assunto é essencial para o desenvolvimento de uma análise crítica sobre um tema que é pouquíssimo questionado (COHN, HILL e RUDDICK, 2005, s/p).

Assim, observa-seque o ambiente securitário global foi construído por meio de discursos baseados em estereótipos de gênero desiguais, prezando por um comportamento masculinizado técnico e agressivo, e da mesma forma, desqualificando qualquer expressão de emoção em relação às possíveis vítimas e ao caos que seria instaurado com uma simples deliberação. O emocional, o concreto, o particular, corpos humanos e sua vulnerabilidade, vidas e suas subjetividades, tudo isso é considerado feminino de acordo com as dicotomias binárias do discurso gendrado (ibid).

A partir do que foi exposto até então, é possível perceber que os homens são ampla maioria nos diversos setores da segurança internacional, principalmente na tomada de decisão. Ademais, os homens são identificados como os principais agentes da agressão, tanto na guerra 
como no ambiente doméstico, predominando em todo espectro da violência (CONELL, 2000, p. 214). O senso comum costuma acreditar e disseminar a ideia de que a violência do homem é natural ou até biológica (ibid, p. 215). Por isso, até as formas mais brutas de agressão como estupro - podem ser consideradas aceitáveis, tendo em vista essa imagem de "natureza agressiva e imutável dos homens" (ibid).

As crençastanto na violência natural do homem, como no instinto maternal e pacífico da mulher,são baseadasnoessencialismo ${ }^{11}$ biológico. As teorias críticas não aceitam estes termos pré-definidos e determinados em suas análises, pois para utilizá-lo em problemas envolvendo identidades seria necessário assumir que as mesmas são simples e fixas, o que não condiz com a realidade. SegundoSkjelsbæk (2001):

Para o essencialismo, diferenças e identidades de gênero são percebidas como o resultado de fatores subjacentes estáveis. A biologia torna-se a fonte primária para explicar as diferenças de comportamentos, atitudes e pensamentos femininos e masculinos. [...] Para os homens que detém o poder, a posição essencialista pode ser utilizada para dizer que há algo no status de poder dos homens que se origina em sua identidade de gênero. $\mathrm{O}$ fato das mulheres terem ficado em casa, cuidando da casa e das crianças, também é explicado em termos da "verdadeira" natureza feminina. (SKJELSBÆK, 2001, p.47)

Este essencialismo identitário tende a criar o problema da generalização. Por exemplo, se levarmos em consideração os altos índices de violência praticados por homens em comparação às mulheres, há uma grade tendência de fortalecer a ideia de que todos os homens são violentos. Connel (2000, p. 226) indica que é preciso ter cuidado com as generalizações através da seguinte premissa: quase todos os soldados são homens, mas a maioria dos homens não são soldados. Muitas formas de masculinidades existem, e além de serem variáveis, as mesmas são estruturadas por hierarquias e exclusões; sendo assim, há um tipo que se sobressai sobre os demais que ficou conhecido, na academia, como masculinidade hegemônica, considerada o centro do sistema de poder gendrado (ibid, p. 228).

As pesquisas pós-positivistas apontam para o fato de que nossas palavras mudam constantemente, sendo assim, se distanciam do essencialismo ao apontar para o fato de que as identidades são determinadas pelas interações sociais, e não pela natureza. Isso quer dizer que quando as pessoas participam de um mundo social, independentemente de serem mulheres ou homens, as mesmas ficam expostas a padrões de comportamentos, os quais muitas vezes enfatizam as diferenças de gênero. Assim, algumas feministas da área concordam com a

\footnotetext{
${ }^{11} \mathrm{O}$ essencialismo é baseado na noção filosófica, a qual aponta que alguns objetos - não interessa como são descritos ou definidos - podem ter certas características que não mudam com o tempo, ou seja, são fixas.
} 
noção de que as identidades são mutáveis; por isso, a análise dos conflitos é elaborada através do gênero como categoria de análise.

Frequentemente, a identidade das mulheres é considerada naturalmente pacífica. Como citado anteriormente, assumir que as identidades são fixas e pré-determinadas acaba acarretando em uma generalização que não se aplica a todos os sujeitos. Contudo, é inegável a participação direta das mulheres como ativistas em movimentos para alcançar a paz. Enloe (1989, p. 14) aponta que a "Liga Internacional de Mulheres para a Paz e a Liberdade" 12 foi fundada por feministas ativistas na questão da paz durante a Primeira Guerra Mundial; e, a partir disso,muitos grupos como este foram criados na década de 1990. Levando em consideração a expansão do ativismo das mulheres foi possível dar origem a novas redes transnacionais, cada qual com suas características históricas e políticas de gênero.

A relevância da análise de gênero nos períodos de guerra reside no fato de que nem todos os conflitos funcionaram a parir da configuração tradicional, nessas situações, as mulheres não viveram o conflito apenas como atores oprimidos e vitimizados. Um exemplo desses casos atípicos é a guerra civil de El Salvador deflagrada em 1980, em que foi possível constatar através de imagens e depoimentos que a presença de mulheres - as quais participavam do conflito ativamente junto aos homens - foi muito significante. Essas mulheres combatentes defendiam a ideologia da libertação não só para alcançar os objetivos referentes à situação política de seu país, como também para conquistar sua própria libertação durante os anos de conflito, especialmente, do machismo e da esfera doméstica(SKJELSBÆK, 2001, p. 58).

A autora Mary Kaldor (2006, p. 12) explica que o estado de guerra, no século XXI, é bastante distinto das guerras convencionais no que tange a seus objetivos, métodos de combate e fontes de financiamento. Para ela, os conflitos contemporâneos giram em torno de identidades políticas e, além de serem mais violentos, são descentralizados. Os papéis de gênero nas guerras acompanham a mudança nos padrões dos conflitos, atualmente, o número de mulheres que participam ativamente das atividades belicosas como lutadoras, soldadas, guerrilheiras e terroristas aumentou de modo exponencial (SJOBERG e VIA, 2010, p. 5). Apesar disso, elas ainda são minorias nessas organizações e ainda não podem ocupar certos cargos de liderança, mesmo assim, as mulheres nunca foram tão ativas como nas novas guerras. A partir destes fatos, em que mulheres participaram ativamente do conflito armado, torna-se ainda mais problemático afirmar que mulheres são inerentemente pacíficas.

\footnotetext{
${ }^{12}$ Women's International League for Peace and Freedom.
} 
Outra visão essencialista é a noção de maternidade que além de ser adotada como um indicador inicial para a transição da menina para mulher, também pode ser considerada como aspecto central da feminilidade (SKJELSBÆK, 2001, p. 62). Esta associação corrobora para legitimar a premissa essencialista de que "todas as mulheres são pacíficas e zelosas". Um elemento crucial que problematiza esta premissa é que, muitas vezes, as mães encorajam seus filhos e maridos para participar da guerra (ibid). Assim, segundo Skjelsbæk(2001, p. 64):

As mulheres podem ser propensas à guerra assim como os homens - e, mais
provável, os homens podem ser igualmente pacíficos como mulheres. Uma
abordagem mais construtiva para a distinção 'propensão para guerra ou para a paz'
pode ser olhar para as diferenças em valores e discursos.(SKJELSB ÆK, 2001, p. 64)

Sendo assim, tendo em vista os novos papéis desempenhados e espaços ocupados pelas mulheres nos cenários belicosos, torna-se fundamental questionar porque as mesmas continuam tendo um status de subordinação, mesmo com sua maior integração e participação na política internacional. Para Spike Peterson (2010) há dois motivos principais para isso:

Primeiro, apesar da inclusão das mulheres em diferentes áreas da política global com maior frequência, suas necessidades como mulheres geralmente permanecem desconsideradas e não solucionadas. As mulheres estão sendo integradas em um mundo que continua definido e moldado pelos interesses e necessidades dos homens. [...] Segundo, a natureza gendrada das estruturas que permanecem no lugar desde antes da integração das mulheres, é igualmente desafiadora. [...] As mulheres integram grupos que já têm seus termos, premissas e normas comportamentais definidos por valores masculinos. (PETERSON, 2010 apud SJOBERG \& VIA, 2010, p. 6)

Ademais, Peterson (2010) argumenta que ao tomar o gênero analiticamente ${ }^{13}$ é possível gerar uma compreensão feminista crucial e transformativa: o privilégio cultural daquilo que é identificado como masculinidade é a chave para naturalizar as relações de poder que constituem múltiplas formas de subjeção (ibid, p. 37). Há uma tendência de pensar no gênero como algo primordialmente relacionado à mulher, quando, na verdade, ele está associado tanto com a masculinidade quanto com a feminilidade. Assim, é possível concluir que as manifestações de gênero estão relacionadas com códigos, normas e regras institucionalizadas ao invés de comportamentos individuais (ibid).

Logo, é imprescindível notar que o gênero é um sistema de significados simbólicos que cria hierarquias sociais baseadas em associações percebidas com características masculinas e femininas (SJOBERG, 2010, p. 3). Esta hierarquia, então, é uma construção social, histórica, cultural; uma característica que estrutura e impacta a vida social, política e econômica, moldando também tanto nosso ambiente como nossa visão sobre o mundo. $\mathrm{O}$

\footnotetext{
${ }^{13} \mathrm{O}$ gênero analítico se refere a um sistema de significação sobre a diferenciação entre masculino-feminino que constituem um código governante (PETERSON, 2010: 37)
} 
gênero - e, consequentemente, as noções de masculinidade e feminilidade - se altera conforme culturas, corpos, identidades e linguagem, ou seja, pode ser definido como um conjunto de discursos que representa, constrói, altera e reforça determinados significados e representações sociais (ibid).

\section{Considerações Finais}

Como fica explícito no presente artigo, apesar do crescimento dos estudos feministas na disciplina, especialmente no que tange à segurança internacional, a produção teórica ainda continua marginalizada. Para Tickner, as mulheres sempre estiveram presentes no campo, mas durante um tempo considerável, elas foram ofuscadas pelas lentes positivistas dominantes da disciplina.Salientando a importância do gênero como categoria de análise, Jill Steans (1998, p.5) argumentou que ao olhar para o mundo através de lentes gendradas é possível perceber o gênero como um tipo particular de relação de poder, ou estabelecer o modo como o gênero é central para o entendimento dos processos internacionais (apud SJOBERG, 2010, p. 2).

Em relação à segurança internacional, Laura Sjoberg (2010, p. 1) apontou que seu estudo e prática permanecem como uma esfera ainda dominada por homens; as mulheres com posições privilegiadas nas tomadas de decisões ainda são raras e muitos textos acadêmicos são encontrados completamente sem referência às mulheres e ao gênero. Por este motivo, a contribuição feminista para os estudos de segurança é de suma importância, pois a mesma é responsável por possibilitar a localização das mulheres nos conflitos e o entendimento sobre como as noções de masculinidades e feminilidades são criadas, frequentemente como identidades pré-fixadas. Sendo assim, o feminismo contribui para a área da segurança internacional, no sentido de fornecer estudos mais amplos sobre o que acontece com os indivíduos e as comunidades durante o período de conflito.

A partir da revisão bibliográfica da teoria feminista de RI foi possível identificar que, nas guerras, e também de maneira geral, as identidades são mutáveis e dinâmicas, e não, universais e naturais. As premissas as quais afirmam que as mulheres são essencialmente pacíficas e os homens necessariamente violentos são problemáticas, pois as identidades não são pré-determinadas ou fixas. Tanto a participação ativa das mulheres na guerra quanto o apoio das mães prestado aos seus filhos e maridos para os mesmos adentrarem ao combate, são exemplos de que não é válido afirmar que as mulheres sempre são maternais e pacíficas por conta de sua natureza. Outro exemplo é a atual vice-secretária geral da OTAN, Rose Gottemoeller, a qual assume uma posição realista e masculinizada tanto em seus discursos 
como na tomada de decisões. Da mesma maneira, os homens não são sempre violentos e guiados por seu "instinto animal e selvagem" como o senso comum e muitos autores afirmam. Essas premissas são essencialistas e, por isso, contribuem para criar estereótipos identitários através da definição de conceitos como "masculinidade" e "feminilidade", os quais se alteram conforme tempo, lugar e cultura.

Um conhecimento preciso, rigoroso e ético na área da segurança não pode ser produzido sem levar em conta a presença das mulheres na política global, ainda mais quando a mesma é composta na maioria por homens. O feminismo faz-se fundamental por seu pioneirismo na adoção do gênero como categoria de análise: sem o mesmo, a produção baseada em preceitos essencialistas continuaria dominante na disciplina sem maiores questionamentos. A partir do presente artigo, ficou claro que é preciso observar as identidades e como as mesmas são adaptáveis conforme a situação em que estão inseridas para entender como o patriarcado detém o uso da força e permanece no poder através de discursos, normas, regras, leis e também quando o assunto é política internacional. Estudar o gênero nas RI é, portanto, estudar as relações de poder.

\section{Referências Bibliográficas}

CHENOY, AnuradhaMitra; VANAIK, Achin. Promoting Peace, Security and Conflict Resolution: Gender Balance in Decisionmaking. In: SKJELSBÆK, Inger; SMITH, Dan. Gender, Peace and Conflict. Londres: Sage Publications, 2001. Cap. 7. p. 122-138.

COHN, Carol; RUDDICK, Sara.A Feminist Ethical Perspective on Weapons of Mass Destruction. Ethics And Weapons Of Mass Destruction, [s.1.], p.405-435, 2003. Cambridge University Press (CUP). Disponível em: <https://genderandsecurity.org>. Acesso em: 14 mar. 2017.

COHN, Carol; HILL, Felicity; RUDDICK, Sara. The Relevance of Gender for Eliminating Weapons of Mass Destruction. The Weapons of Mass Destruction Commission, Estocolmo, v. 38, p.1-12, jun. 2005. Disponível em: <https://genderandsecurity.org>. Acesso em: 14 mar. 2017.

CONNELL, Raewyn. The men and the boys. Austrália: Allen e Unwin, 2000. 270 p.

COOKE, Mariam G.; WOOLLACOTT, Angela. Gendering war talk. Nova Jérsei: Princeton University Press, 1993. 352 p. (Princeton Legacy Library). Disponível em: <http://www.jstor.org/>. Acesso em: 14 mar. 2017.

ENLOE, Cynthia. Bananas, Beaches and Bases: Making Feminist Sense of International Politics. 2. ed. Berkeley And Los Angeles, California: University Of California Press, 1989. $429 \mathrm{p}$. 
KALDOR, Mary. New and Old Wars: Organized Violence in a Global Era. Stanford, Califórnia: Stanford University Press, 1999. 68 p.

KEOHANE, Robert O.. International Relations Theory: Contributions of a Feminist Standpoint. Millennium, [s.1.], v. 18, n. 2, p.245-253, jun. 1989.SAGE Publications. http://dx.doi.org/10.1177/03058298890180021001. Disponível em: < http://mil.sagepub.com >. Acesso em: 14 mar. 2017.

MONTE, Isadora Xavier. Gênero e Relações Internacionais: Uma crítica ao discurso tradicional de segurança. 2010. 146 f. Dissertação (Mestrado) - Curso de Relações Internacionais, Instituto de Relações Internacionais da Universidade de Brasilia, Brasília, 2010 .

PARPART, Jane L.; ZALEWSKI, Marysia. Rethinking the Man Question: sex, gender and violence in international relations.Londres e Nova Iorque: Zed Books, 2008. 234 p.

PETTMAN, Jan Jin. Worlding Women: A Feminist International Politics. Londres e Nova Iorque: Routledge, 1996. 218 p.

SJOBERG, Laura. Gender and International Security: Feminist Perspectives. Londres e Nova Iorque: Routledge, 210. 303 p.

SJOBERG, Laura; VIA, Sandra. Gender, War and Militarism: Feminist Perspectives. Santa Barbara, Califórnia: Praeger Security International, 2010. 301 p.

SKJELSBÆK, Inger; SMITH, Dan. Gender, Peace and Conflict. Londres: Sage Publications, 2001. 239 p.

SYLVESTER, Christine. Feminist International Relations: An Unfinished Journey. Cambridge, United Kingdom: Cambridge University Press, 2004. 369 p.

TICKNER, J. Ann. You Just Don't Understand: Troubled Engagements Between Feminists and IR Theorists. International Studies Quarterly, [s.1.], v. 41, n. 4, p.611-632, dez. 1997. Oxford University Press (OUP). http://dx.doi.org/10.1111/1468-2478.00060. Disponível em: <https://www.jstor.org>. Acesso em: 14 mar. 2017.

TICKNER, J. Ann. Gendering World Politics. Nova Iorque: Columbia University Press, 2001.214 p.

WEBER, Cynthia. Good Girls, Little Girls, and Bad Girls: Male Paranoia in Robert Keohane's Critique of Feminist International Relations. Millennium, [s.1.], v. 23, n. 2, p.337349, jun. 1994.SAGE Publications. http://dx.doi.org/10.1177/03058298940230021401. Disponívelem: <http://mil.sagepub.com>. Acessoem: 14 mar. 2017. 